\title{
Vinylester and Polyester 3D Printing
}

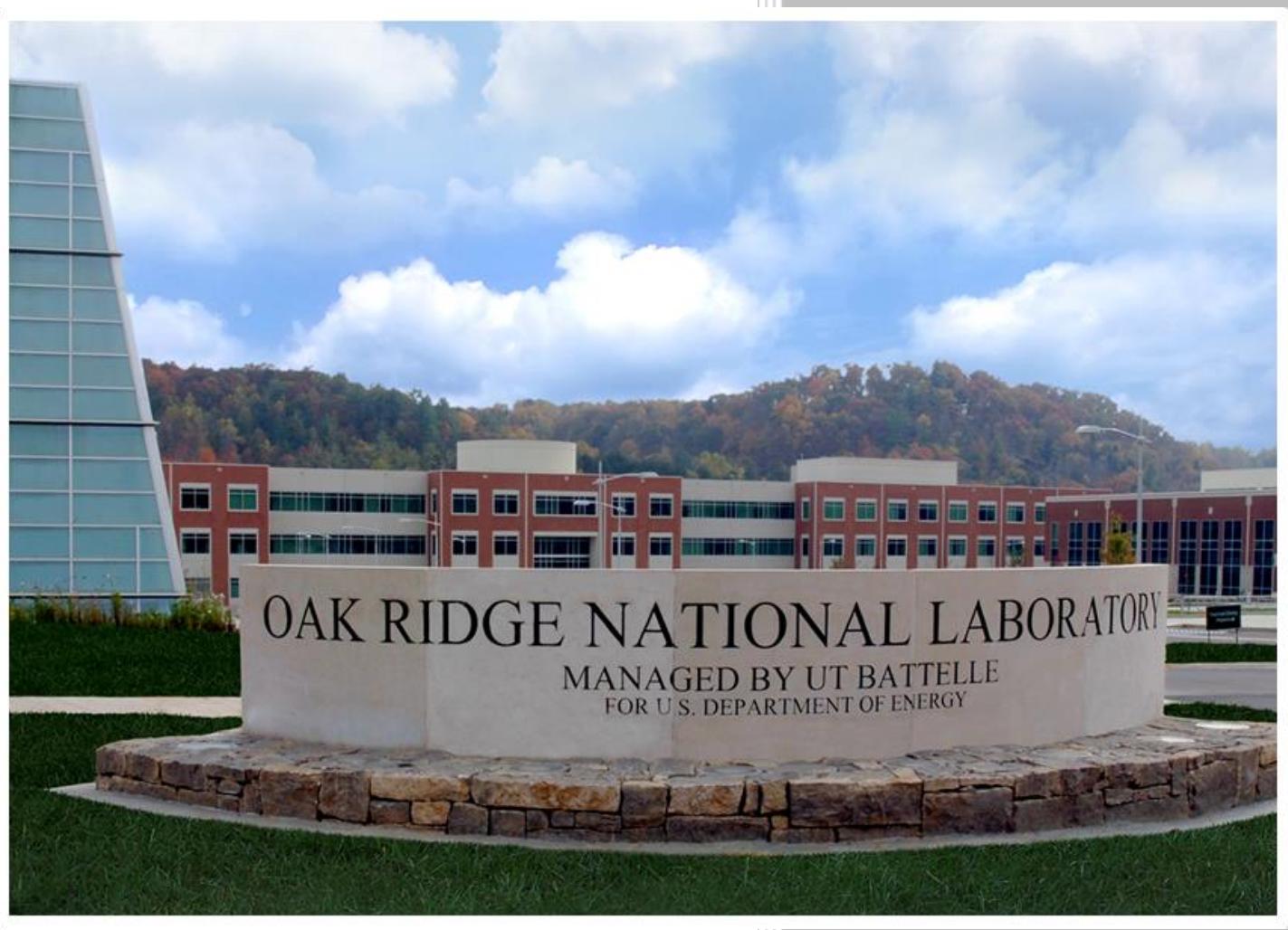

Vlastimil Kunc

October 24, 2019

CRADA FINAL REPORT

NFE-17-06792

Approved for Public Release.

Distribution is Unlimited. 


\section{DOCUMENT AVAILABILITY}

Reports produced after January 1, 1996, are generally available free via US Department of Energy (DOE) SciTech Connect.

Website http://www.osti.gov/scitech/

Reports produced before January 1, 1996, may be purchased by members of the public from the following source:

National Technical Information Service
5285 Port Royal Road
Springfield, VA 22161
Telephone 703-605-6000 (1-800-553-6847)
TDD 703-487-4639
Fax 703-605-6900
E-mail info@ntis.gov
Website http://www.ntis.gov/help/ordermethods.aspx

Reports are available to DOE employees, DOE contractors, Energy Technology Data Exchange representatives, and International Nuclear Information System representatives from the following source:

Office of Scientific and Technical Information

PO Box 62

Oak Ridge, TN 37831

Telephone 865-576-8401

Fax 865-576-5728

E-mail reports@osti.gov

Website http://www.osti.gov/contact.html

This report was prepared as an account of work sponsored by an agency of the United States Government. Neither the United States Government nor any agency thereof, nor any of their employees, makes any warranty, express or implied, or assumes any legal liability or responsibility for the accuracy, completeness, or usefulness of any information, apparatus, product, or process disclosed, or represents that its use would not infringe privately owned rights. Reference herein to any specific commercial product, process, or service by trade name, trademark, manufacturer, or otherwise, does not necessarily constitute or imply its endorsement, recommendation, or favoring by the United States Government or any agency thereof. The views and opinions of authors expressed herein do not necessarily state or reflect those of the United States Government or any agency thereof. 
ORNL/TM-2019/1404

CRADA/NFE-17-06792

Energy and Transportation Science Division

Advanced Manufacturing Office

\title{
Vinylester and Polyester 3D Printing
}

\author{
Authors \\ Vlastimil Kunc \\ Christopher Hershey \\ John Lindahl \\ Stian Romberg \\ Steve Voeks \\ Mark Adams
}

Date Published:

October 24, 2019

\footnotetext{
Prepared by

OAK RIDGE NATIONAL LABORATORY

Oak Ridge, Tennessee 37831-6283

managed by

UT-BATTELLE, LLC

for the

US DEPARTMENT OF ENERGY

under contract DE-AC05-00OR22725
}

Approved For Public Release 



\section{CONTENTS}

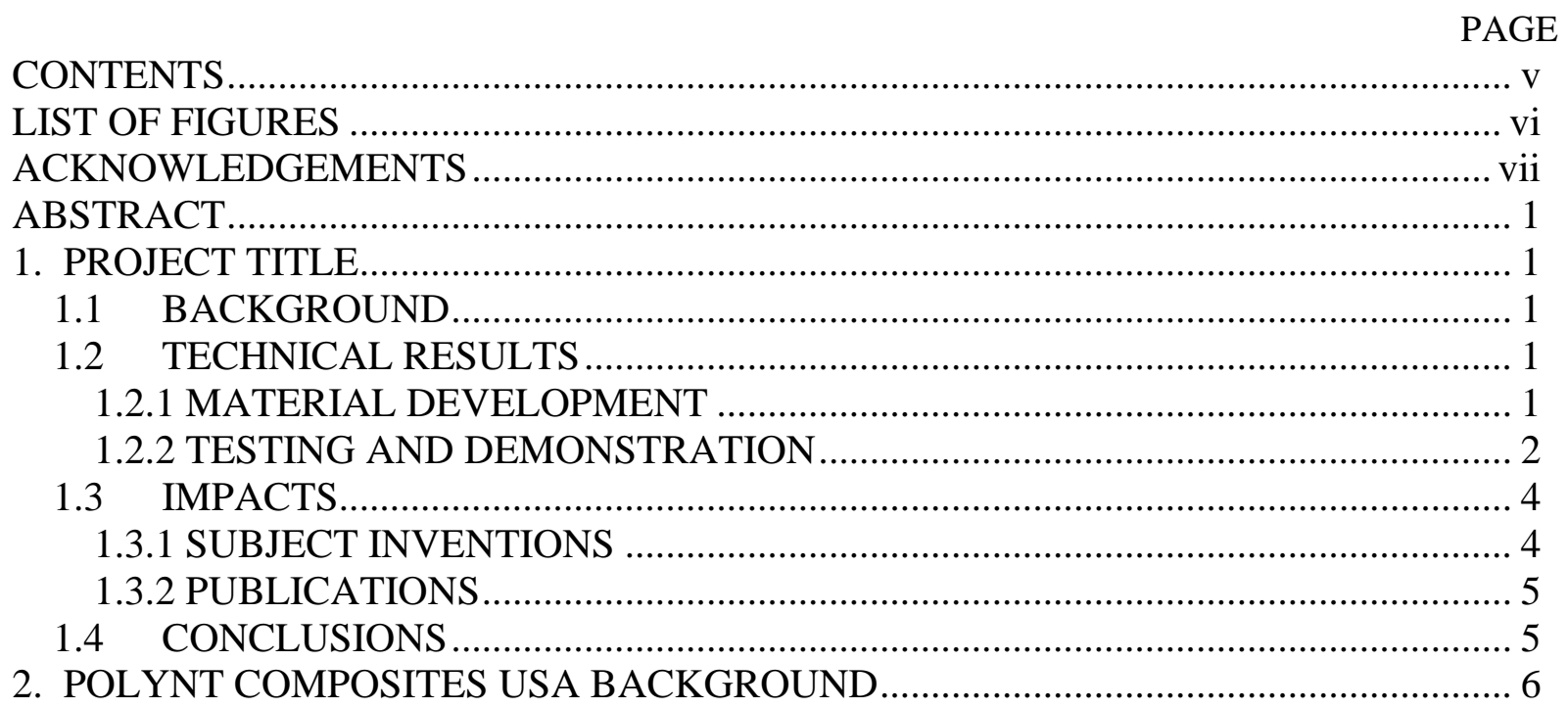




\section{LIST OF FIGURES}

Fig. 1. (Left) Standard test print geometry with optical and IR imaging. (Right) IR image during build.

Fig. 2. Properties of cured printed PRD-1520

Fig. 3. (a) PRD-1520 printed mold, (b) High build coating and machining, (c) Finished mold for gel coat, (d) Gel coated and polished mold, (e) Sprayed silicon bag, (d) Carbon fiber kayak paddle.....

Fig 4. (left) ORNL management, Polynt, and Magnum Venus Products Development team at launch, (Right) Conference room prior to launch of material. ........................................... 4 


\section{ACKNOWLEDGEMENTS}

This CRADA NFE-17-06792 was conducted as a Technical Collaboration project within the Oak Ridge National Laboratory (ORNL) Manufacturing Demonstration Facility (MDF) sponsored by the US Department of Energy Advanced Manufacturing Office (CPS Agreement Number 24761).

Opportunities for MDF technical collaborations are listed in the announcement "Manufacturing Demonstration Facility Technology Collaborations for US Manufacturers in Advanced

Manufacturing and Materials Technologies" posted at http://web.ornl.gov/sci/manufacturing/docs/FBO-ORNL-MDF-2013-2.pdf. The goal of technical collaborations is to engage industry partners to participate in short-term, collaborative projects within the Manufacturing Demonstration Facility (MDF) to assess applicability and of new energy efficient manufacturing technologies. Research sponsored by the U.S. Department of Energy, Office of Energy Efficiency and Renewable Energy, Advanced Manufacturing Office, under contract DE-AC0500OR22725 with UT-Battelle, LLC. 


\begin{abstract}
In Phase 2 of the technical collaboration between Oak Ridge National Laboratory (ORNL) and Polynt Composites USA, a vinyl ester composite material for extrusion deposition additive manufacturing (AM) of thermoset materials was developed, characterized, and functionality demonstrated. Through this work modeling capability was developed to determine the desired in use material characteristics and refined process parameters. Coupon level testing was performed to validate the end use functionality of printed structures. Finally, the material was printed to evaluate its performance in composites tooling applications. This combined effort led to a commercial product, PRD-1520, for Polynt Composites USA specifically designed for large-scale extrusion deposition additive manufacturing of thermoset materials.
\end{abstract}

\title{
1. PROJECT TITLE
}

This Phase 2 technical collaboration project (MDF-TC-2017-119) began on October 23, 2018 and was completed on September 17, 2019. The collaboration partner Polynt Composites USA is a large business. ORNL and Polynt developed a vinylester composite resin for large scale extrusion 3D printing that is now a commercially available product.

\subsection{BACKGROUND}

Polynt Composites USA Inc. is a leading supplier of gel coats, composite resins, and industrial cleaners in the United States. Polynt resins have been optimized to be processed using various application technologies such as hand lay-up, spray-up, casting, pultrusion, filament winding, sheet molding compound (SMC), bulk molding compound (BMC), infusion, injection, resin transfer molding (RTM), etc. This Phase 2 technical collaboration focused on refining and demonstrating the capabilities of the vinylester material developed in Phase 1.

\subsection{TECHNICAL RESULTS}

Phase 2 of this project focused on the development of a commercially available product for largescale reactive polymer additive manufacturing. A standard test process and geometry were developed to determine the desired cure kinetics and processing parameters. A demonstration article was manufactured to prove the technology, and the demonstration article was shown in the CAMX 2019 Demo Zone. The project concluded with a public material launch on September 17, 2019.

\subsubsection{Material Development}

In Phase 1 of the project, over 20 different formulated systems and 3 different peroxides were tested for their printing viability. Out of these options, 1 material system and 1 organic peroxide were chosen, PRD-1520 and CHP Peroxide. Throughout Phase 2, Polynt worked to refine and optimize the rheological and filler packages within the PRD-1520 to provide the optimal printing and postdeposition mechanical properties. Process parameters were optimized by the development of a standard test print geometry specifically designed for reactive polymer printing at ORNL (Fig. 1). 

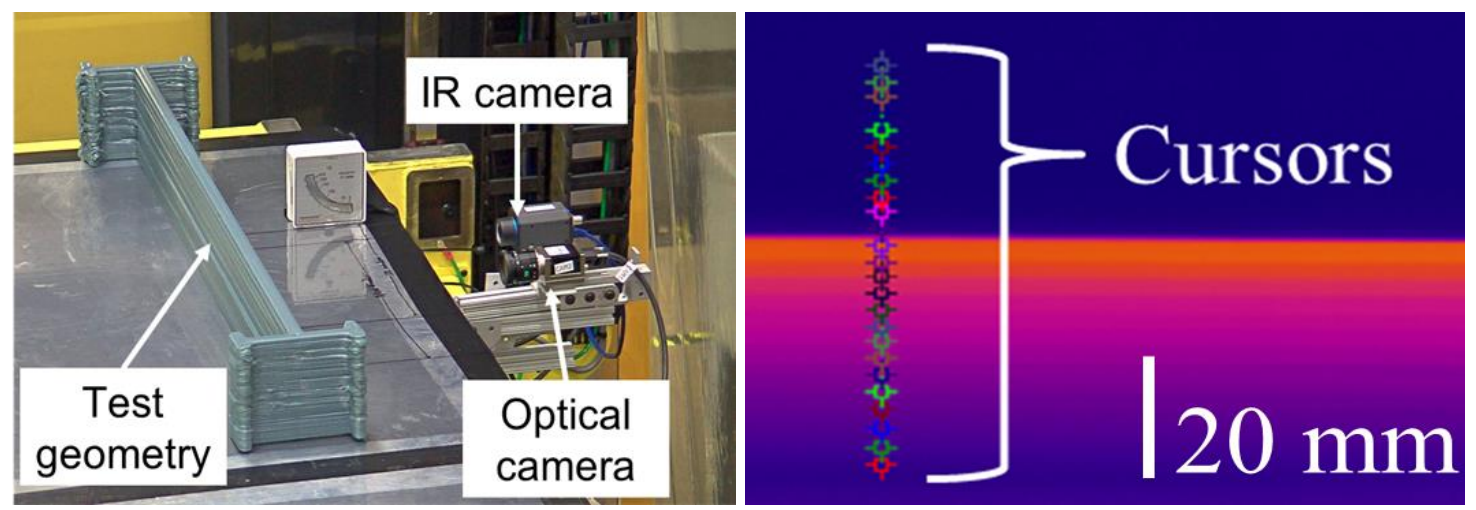

Fig. 1. (Left) Standard test print geometry with optical and IR imaging. (Right) IR image during build.

This test consisted of an H-bar geometry to simulate a semi-infinite thin wall. An IR camera was used to capture the temperature profile at the wall during printing. The optical camera was used to measure any sagging or deviation from the as-deposited shape during the curing process. A layer time sweep of the standard test geometry illustrated the challenges associated with this new large-scale printing technique. Three distinct failure modes were identified, including viscoelastic collapse, exotherminduced collapse, and printhead collision due to warpage. Information from both cameras provided insight to avoiding exotherm-induced collapse, which is unique to printing exothermic materials. The maximum temperature experienced by each layer and the time to reach that temperature are key parameters causing this type of failure. These findings informed the selection of a successful layer time and guided the implementation of material alterations to expand the range of successful layer times. In addition, a finite difference numerical model was generated using an adiabatic temperature rise, a probe of the resin temperature sensitivity, and several different temperature ramp rate tests. Excellent agreement was found between the model and the experiments, providing a new tool to evaluate the printability of new materials with a few rheological tests. While multiple parameters such as gantry speed, deposited bead size, layer height, etc. were tested, the best results were shown with these processing parameter sets in Table 1.

Table 1. Processing parameters for PRD-1520

\begin{tabular}{|c|c|c|c|c|c|}
\hline $\begin{array}{c}\text { Gantry Speed } \\
\text { (in/s) }\end{array}$ & $\begin{array}{c}\text { Layer Height } \\
\text { (in) }\end{array}$ & $\begin{array}{c}\text { Bead Width } \\
\text { (in) }\end{array}$ & $\begin{array}{c}\text { Flow Rate } \\
\text { (lb/hr) }\end{array}$ & $\begin{array}{c}\text { Minimum } \\
\text { Layer Time } \\
\text { (min) }\end{array}$ & $\begin{array}{c}\text { Nozzle } \\
\text { Diameter (in) }\end{array}$ \\
\hline 2.7 & 0.11 & 0.275 & 15 & 4.5 & 0.2 \\
\hline
\end{tabular}

\subsubsection{Testing and Demonstration}

Standard composite testing methods were used to characterize the final developed formula for PRD1520. Two primary directions were tested from the printed H-bar geometry, in the deposition direction (X-axis) and the direction normal to the build plane (Z-axis). The PRD-1520 material showed excellent property retention in both directions when compared to standard large-scale printed thermoplastic material. Figure 2 shows the properties for the printed material from the supplier's technical data sheet for the PRD-1520 material. 


\begin{tabular}{|c|c|c|c|c|c|}
\hline PROPERTIES - CURED $^{4}$ & & & & & \\
\hline Property $^{5}$ & Unit & $\mathrm{X}$ - axis & Z-axis & $\begin{array}{c}\% \\
\text { Retention }\end{array}$ & $\begin{array}{c}\text { Test } \\
\text { Method }\end{array}$ \\
\hline Tensile Strength & psi & 6940 & 3465 & 50.0 & ASTM D 638 \\
\hline Tensile Modulus & psi & 606,000 & 570,000 & 94.0 & ASTM D 638 \\
\hline Tensile Elongation & $\%$ & 1.97 & 0.78 & 39.6 & ASTM D 638 \\
\hline Flexure Strength & psi & 9,920 & 6,330 & 63.8 & ASTM D 790 \\
\hline Flexure Modulus & psi & 560,000 & 475,000 & 84.8 & ASTM D 790 \\
\hline Compressive strength & psi & 375,238 & 312,026 & 83.2 & ASTM D 695 \\
\hline $\begin{array}{l}\text { Heat Deflection } \\
\text { Temperature }^{6}\end{array}$ & ${ }^{\circ} \mathrm{C} /{ }^{\circ} \mathrm{F}$ & $94 / 201$ & $94 / 201$ & 100 & ASTM D 648 \\
\hline Glass transition temp, $\mathrm{Tg}^{7}$ & ${ }^{\circ} \mathrm{C} /{ }^{\circ} \mathrm{F}$ & $107 / 225$ & $106 / 223$ & 99.1 & $\begin{array}{c}\text { ASTM D } \\
5279\end{array}$ \\
\hline
\end{tabular}

4)Physical properties were determined using internal Polynt test methods that are șimilar to those listed above. 5) Data collected on parts printed with MVP RAM, 2.5\% CHP Peroxide. Post cured for 2 hrs. each @ $65,121,160^{\circ} \mathrm{C}$ 6) By DMA on TA RSA-3

7) By DMA on TA Q800

8) By TMA on TA Q 400 analyzer, $30-97^{\circ} \mathrm{C}$.

Fig. 2. Properties of cured printed PRD-1520

Other properties to note are for the uncured resin. The viscosity of PRD-1520 ranges from 2.5-3.0 million cPs, and the gel time for this material when used with the desired peroxide for printing, CHP, is 20-25 minutes. Ranges for both values are given due to their dependence on the ambient temperature during printing.

Polynt and ORNL demonstrated this technology in the Demo Zone at CAMX 2019. This is the largest composites conference in the United States, thus the best possible audience to showcase this new material and technology. A silicone bag vacuum assisted resin transfer molding (VARTM) mold to make a carbon fiber kayak paddle was the chosen demonstration article. The mold was printed using PRD-1520 in under 3 hours. After printing the mold and aligning it within the router for placing relocating fiducials, a high build coating was sprayed onto the mold at an outside shop. The mold was then brought back to ORNL for machining. Once machining was complete the mold was gel coated and polished. A wax pattern was then used to mimic the paddle shape, and a silicone bag was sprayed onto the surface of the mold. Finally, the mold and bag were used to infuse dry carbon fibers with resin to create the kayak paddle. The entire workflow can be seen in Figure 3. 


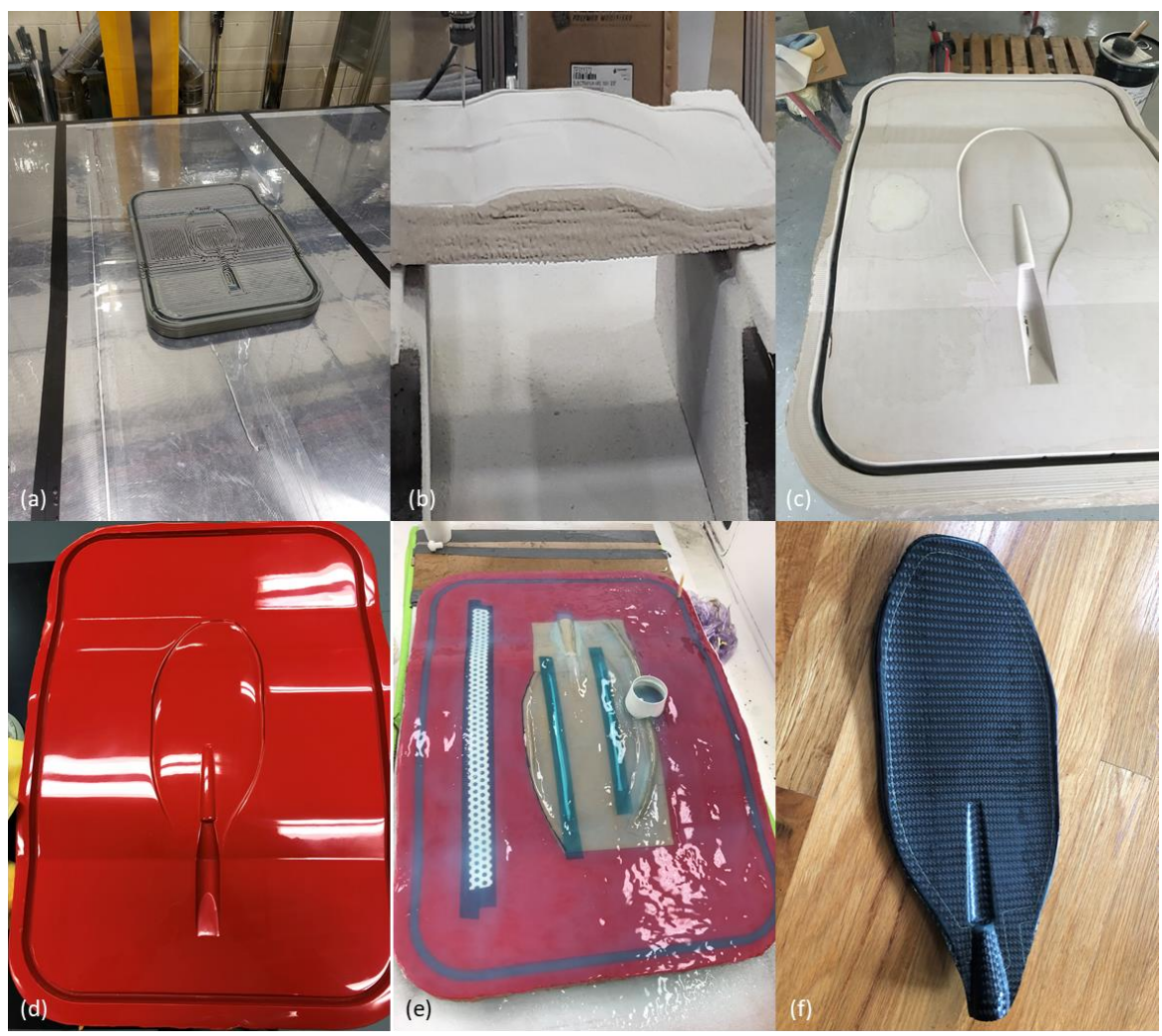

Fig. 3. (a) PRD-1520 printed mold, (b) High build coating and machining, (c) Finished mold for gel coat, (d) Gel coated and polished mold, (e) Sprayed silicon bag, (d) Carbon fiber kayak paddle

\section{$1.3 \quad$ IMPACTS}

This project successfully led to the development and public launch on September 17, 2019 of a vinyl ester resin system specifically designed around large-scale extrusion deposition additive manufacturing of thermoset materials (Fig. 4). This material requires no energy input in the form of heat to process or cure. This reduces the required energy needed to build molds with additive manufacturing. Polynt now offers this material for purchase and is the first company to now have an off the shelf product for this process.

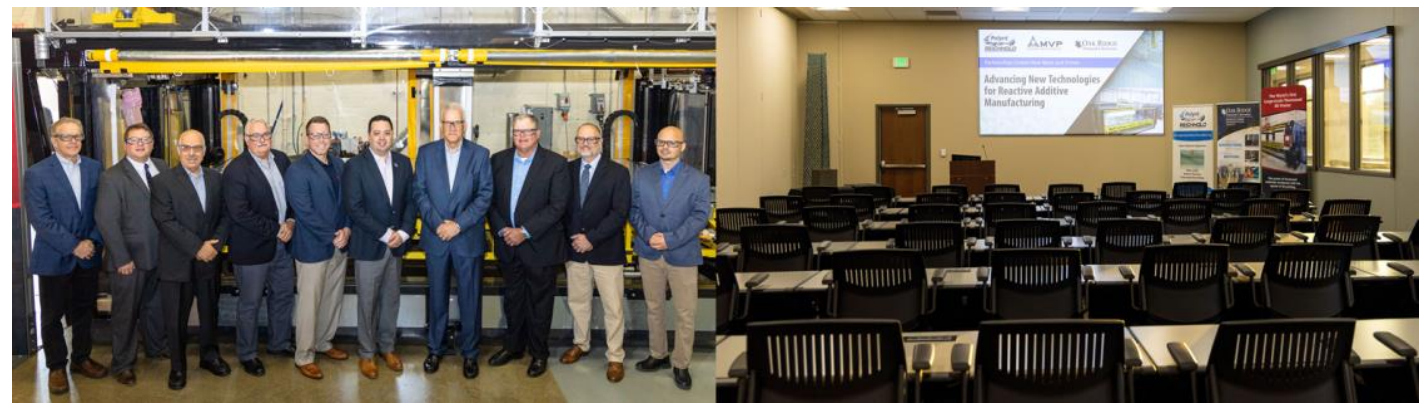

Fig 4. (left) ORNL management, Polynt, and Magnum Venus Products Development team at launch, (Right) Conference room prior to launch of material.

\subsubsection{Subject Inventions}

US Patent Application No. 62/854,857 filed on May 30, 2019. 


\subsubsection{Publications}

1. Kunc, V., et al., Low cost reactive polymers for large scale additive manufacturing. CAMX 2018, Dallas, TX, Oct. 15-18, 2018. The Composites and Advanced Materials Expo.

2. Lindahl, J., et al., Large-scale additive manufacturing with reactive polymers. CAMX 2018, Dallas, TX, Oct. 15-18, 2018. The Composites and Advanced Materials Expo.

3. Romberg, S., et al., Large-scale additive manufacturing of highly exothermic reactive polymer systems. SAMPE 2019, Charlotte, NC, May 20-23, 2019. Society for the Advancement of Material and Process Engineering.

4. Hershey, C., et al., Large-scale reactive extrusion deposition of sparse infill structures with solid perimeters. CAMX 2019, Anaheim, CA, Sep 23-26, 2019. The Composites and Advanced Materials Expo.

\subsection{CONCLUSIONS}

In conclusion, this project was successful in meeting all the requirements that would lead to final product for Polynt. The material was characterized and used to demonstrate an application in composites tooling. Polynt's capabilities in material formulation and synthesis coupled with ORNL's additive manufacturing expertise were critical to the success of this project. The next steps for this technology would center around testing and demonstration the feasibility of using this material in different tooling applications such as reaction injection molding, thermoforming, and fixturing. Polynt now plans to work with ORNL in the future for the development of more material systems for large-scale extrusion deposition additive manufacturing of thermoset materials. 


\section{POLYNT COMPOSITES USA BACKGROUND}

Polynt Composites USA, Inc. is one of the leading companies in the production and sale of unsaturated polyester resin, urethane ester, and vinyl ester, which are produced under DISTITRON® and other trade names. Polynt is a leading supplier of gel coats, composite resins, and industrial cleaners in the United States. Polynt resins have been optimized to be processed using various application technologies such as hand lay-up, spray-up, casting, pultrusion, filament winding, sheet molding compounds-bulk molding compounds, infusion, injection, resin transfer molding, etc. 